\title{
Advances in the Development of Host Resistance in Corn to Aflatoxin Contamination by Aspergillus flavus
}

\author{
R. L. Brown, Z.-Y. Chen, T. E. Cleveland, and J. S. Russin
}

First and third authors: Southern Regional Research Center, USDA-ARS, New Orleans, LA 70179; second and fourth authors: Department of Plant Pathology and Crop Physiology, Louisiana State University Agricultural Center, Baton Rouge, LA 70803. Accepted for publication 26 October 1998.

\begin{abstract}
Brown, R. L., Chen, Z.-Y., Cleveland, T. E., and Russin, J. S. 1999. Advances in the development of host resistance in corn to aflatoxin contamination by Aspergillus flavus. Phytopathology 89:113-117.

Aflatoxins are toxic, highly carcinogenic secondary metabolites of Aspergillus flavus and A. parasiticus, which when produced during fungal infection of a susceptible crop in the field or after harvest contaminate food and feed and threaten human and animal health. Although there are several management strategies that may reduce aflatoxin contamination of corn, the preeminent strategy for elimination of aflatoxin is to develop preharvest host resistance to aflatoxin accumulation. This strategy has gained even greater prominence due to recent discoveries of natural resistance in corn that can be exploited in plant-breeding strategies. The ability to identify resistant corn genotypes has been enhanced by the de-
\end{abstract}

ABSTRACT velopment of a laboratory kernel-screening assay and by a strain of A. flavus genetically engineered to produce $\beta$-glucuronidase, an enzyme whose activity can be monitored to assess the degree of fungal infection in kernels. Investigations of resistant corn genotypes have associated kernel pericarp wax characteristics with resistance, identified kernel proteins associated with resistance to and inhibition of fungal growth or aflatoxin biosynthesis, and identified chromosome regions associated with resistance to Aspergillus ear rot and aflatoxin production. Such research advances could lead, in the near future, to commercially available, agronomically acceptable corn lines with multiple preharvest resistances to aflatoxin contamination.

Additional keywords: crop resistance, mycotoxins, preharvest aflatoxin elimination.
Aflatoxins, the toxic, highly carcinogenic secondary metabolites of Aspergillus flavus and A. parasiticus, are the most widely investigated mycotoxins due to their role in establishing the significance of mycotoxins in animal diseases and regulation of aflatoxin contamination in foods (45). Aflatoxins pose serious health hazards to humans and domestic animals because they frequently contaminate agricultural commodities $(9,12)$. More than 50 countries have established or proposed regulations for controlling aflatoxins in foods and feeds (18). The U.S. Food and Drug Administration (FDA) has set limits of $20 \mathrm{ppb}$, total aflatoxins, for interstate commerce of food and feed and $0.5 \mathrm{ppb}$ of aflatoxin $\mathrm{M}_{1}$ for sale of milk. Recognition of the need to control aflatoxin contamination of food and feed grains, potential health hazards of contamination, and strict governmental regulation has elicited a variety of approaches from researchers to eliminate aflatoxins from susceptible crops, such as corn, cottonseed, peanut, and tree nuts. However, development of preharvest host resistance to aflatoxin contamination is probably the best and most widely explored strategy, because $A$. flavus infects affected crops prior to harvest (25). The preeminence of the host resistance strategy in corn production also is due to several recent research advances. The purpose of our review is to highlight recent advances in and their contributions to the development of corn host resistance against aflatoxin contamination.

\section{CURRENT PRACTICES FOR MANAGING AFLATOXIN CONTAMINATION}

Preventive measures for controlling aflatoxin contamination in the field focus on prevention of fungal penetration, growth, and

Corresponding author: R. L. Brown; E-mail address: rbrown@nola.srrc.usda.gov

Publication no. P-1998-1124-01V

This article is in the public domain and not copyrightable. It may be freely reprinted with customary crediting of the source. The American Phytopathological Society, 1999. subsequent toxin formation in seeds. Preventive measures (other than breeding for resistance) include good cultural practices, harvesting at the optimum stage of maturity and rapid drying after harvesting, and chemical control (26). Aflatoxigenic fungi can grow at very high temperatures (up to $48^{\circ} \mathrm{C}$ ) and at low water potentials (-35 MPa) (24). Under the extreme conditions associated with drought in temperate agricultural crops, aflatoxigenic fungi become very competitive and may become the dominant fungal species in soil. Drought stress also may compromise kernel integrity and health, increasing the rate of fungal infection. Cultural practices, such as irrigation, to reduce plant stress can be effective in reducing aflatoxin contamination of corn. However, irrigation is not always available or cost-effective for growers (31).

Other cultural practices involving tillage systems and crop rotation can affect soil inoculum availability and root/soil interface (alleviating stress during later plant development) and prevent inoculum buildup (20). These practices require further investigation to determine their effectiveness in limiting preharvest aflatoxin contamination (20). Harvesting practices, such as altering harvesting combines to separate damaged kernels, which can contain high levels of aflatoxins, can eliminate some contamination; aflatoxins, however, diffuse away from A. flavus mycelia, and seeds with no visible evidence of fungal infection can contain significant levels of aflatoxins (18).

Because aflatoxin buildup in the field occurs late in crop development, growers may harvest corn early at high moisture contents (26 to 28\%) and dry corn by artificial methods to less than $13 \%$ moisture content. Early harvesting and rapid drying effectively stop aflatoxin accumulation $(20,32)$; however, the risk of further aflatoxin contamination has to exceed the expense involved in early harvesting and artificial drying for this practice to be employed (20). Also, early harvesting is of limited usefulness in regions with little late-season rainfall or where maturation occurs during hot periods of the year.

Conventional methods of plant disease control, such as fungicide use, are ineffective in controlling A. flavus infection of corn 
when employed at concentrations that are both cost-effective and environmentally safe (1). Because A. flavus is a wound pathogen, it is not surprising that insect damage often correlates with aflatoxin contamination of corn (30). Employing insecticides to control insect damage and limit aflatoxin levels also has to prove costeffective and safe. As a result, conventional practices are available that may reduce aflatoxin concentrations in the field, but these practices can involve substantial, unacceptable cost to the grower.

\section{Treating Contaminated Corn}

Decontamination of aflatoxin-contaminated corn can be achieved by various physical, chemical, and biological methods (37). Ammoniation is the most promising method (33). Ammoniation, using either ammonium hydroxide or gaseous ammonia, reduces aflatoxin levels by more than $99 \%$ in corn (18). However, in the United States, the FDA does not permit ammoniation as a method of reducing aflatoxin levels in feedstuffs for interstate commerce, although ammoniation is used domestically in a few states (Texas, North Carolina, Georgia, and Alabama) (18). Decontamination of corn using ozone gas $\left(\mathrm{O}_{3}\right)$ may be a possible alternative to ammoniation (27).

As stated earlier, preharvest host resistance to aflatoxin contamination of corn is potentially the best strategy for controlling contamination, because it focuses on inhibition of fungal colonization of the host plant and/or toxin production by A. flavus on the host plant. Preharvest host resistance would eliminate the need to detoxify large quantities of aflatoxin-contaminated seed and avoid the uncertainties inherent in gaining regulatory agency approval for detoxification procedures.

\section{DEVELOPING HOST RESISTANCE THROUGH PLANT-BREEDING STRATEGIES}

\section{Limitations of Traditional Resistance-Screening Methods}

Screening corn for resistance to kernel infection by A. flavus or resistance to aflatoxin production is a more difficult task than screening for most diseases. Successful screening, in the past, has been hindered (23) by the lack of (i) a resistant control, (ii) inoculation methods yielding infection or aflatoxin levels high enough to differentiate among genotypes (natural infection is undependable), (iii) repeatability across different locations and years, and (iv) rapid and inexpensive methods for assessment of fungal infection and aflatoxin levels.

Several inoculation methods, including pinbar inoculation (for inoculating kernels through husks), silk inoculation, and infestation of corn ears with insect larvae infected with A. flavus conidia, have been tried with varying degrees of success $(22,38)$. The methods each can be useful; however, clarity must exist as to the actual resistance trait to be measured (e.g., husk tightness, silk traits,

TABLE 1. $\beta$-Glucuronidase (GUS) activity and aflatoxin production in inoculated kernels of resistant (MI82) and susceptible (33-16) maize inbreds ${ }^{\mathrm{w}}$

\begin{tabular}{llcc}
\hline Inbred & Treatment & $\begin{array}{c}\text { GUS activity }^{\mathrm{x}} \\
(\mathrm{nmol} \mathrm{MU} / \mathrm{min} / \mathrm{mg})\end{array}$ & $\begin{array}{c}\text { Aflatoxin } \mathrm{B}_{1}{ }^{\mathrm{y}} \\
(\mathrm{ng} / \mathrm{g})\end{array}$ \\
\hline MI82 & Nonwounded & $7 \mathrm{c}^{\mathrm{z}}$ & $56 \mathrm{~d}$ \\
& Endosperm-wounded & $7 \mathrm{c}$ & $313 \mathrm{c}$ \\
& Embryo-wounded & $45 \mathrm{~b}$ & $5,439 \mathrm{~b}$ \\
$33-16$ & Nonwounded & $137 \mathrm{a}$ & $19,797 \mathrm{a}$ \\
& Endosperm-wounded & $208 \mathrm{a}$ & $47,718 \mathrm{a}$ \\
& Embryo-wounded & $192 \mathrm{a}$ & $27,221 \mathrm{a}$ \\
\hline
\end{tabular}

${ }^{\text {w }}$ Table 1 was adapted from Brown et al. (8).

${ }^{x}$ GUS activity was expressed as nanomoles MU (methylumbelliferone) produced per minute per milligram of kernel protein.

${ }^{y}$ Aflatoxin $B_{1}$ was measured in nanograms per gram of extracted kernel dry weight.

${ }^{z}$ Values in a column followed by the same letter are not significantly different by the LSD test. Data were log-transformed prior to analyses to equalize variances. kernel pericarp barrier, or wounded kernel resistance) before an appropriate technique can be employed. Silk inoculation, which is possibly more dependent on plant physiological stage and environmental conditions, is the most inconsistent of the inoculation methods (28).

Plating kernels to determine the frequency of kernel infection and examining kernels for emission of bright greenish yellow fluorescence are methods used to assess A. flavus infection (23). Although both methods can indicate the presence of $A$. flavus in seed, neither can provide the kind of accurate quantitative or tissuelocalization data useful for effective resistance breeding. Several protocols have been developed and used for separation and relatively accurate quantitation of aflatoxins $(36,42)$.

\section{Identification of Resistant Germ Plasm}

Most efforts aimed identifying resistant corn genotypes, until recently, were successful only to a very limited extent (41). The hindrances to resistance screening discussed above played key roles in the lack of success (35). However, two resistant inbred lines (Mp420 and Mp313E) were discovered and tested in field trials at different locations and released as sources of resistant germ plasm $(35,43)$. Pinbar inoculation was one of the methods employed in initial trials and contributed to the separation of resistant from susceptible lines (35). Several inbred lines demonstrating resistance to aflatoxin contamination in Illinois field trials (in which a modified pinbar-inoculation technique was employed) also were discovered (7). The corn breeding population, GT-MAS:gk, is another source of resistant germ plasm. The population was derived from visually classified, segregating kernels obtained from a single fungus-infected hybrid ear (41). GT-MAS:gk tested as resistant over a 5-year period in trials in which a kernel knife-inoculation technique was used.

The discovery of resistant germ plasm may have been facilitated by the use of inoculation techniques capable of repeatedly providing infection or aflatoxin levels high enough for genotype separation to occur. These corn lines generally do not possess commercially acceptable agronomic traits; however, they may be invaluable sources of resistance genes and, as such, provide a basis for rapid development of host-resistance strategies for eliminating aflatoxin contamination.

\section{New Screening Methods}

A laboratory kernel-screening assay (KSA) was developed and used to study resistance to aflatoxin production in GT-MAS:gk kernels (6). KSA uses a very simple and inexpensive apparatus with bioassay trays, petri dishes, vial caps as seed containers, and chromatography paper for holding moisture (4). Kernels screened by KSA are maintained in $100 \%$ relative humidity (RH) at a temperature favoring A. flavus $\left(31^{\circ} \mathrm{C}\right)$ growth and aflatoxin production and usually are incubated for 7 days. Aflatoxin data from KSA experiments can be obtained 2 weeks after experiments are initiated.

KSA experiments confirmed GT-MAS:gk resistance to aflatoxin production and demonstrated that it is maintained even when the pericarp barrier in otherwise viable kernels is breached (6). Penetration through the pericarp barrier was achieved by wounding the kernel with a hypodermic needle down to the endosperm prior to inoculation. Wounding facilitates differentiation between the resistance mechanisms and manipulation of aflatoxin levels in kernels for comparison with other traits (e.g., fungal growth and protein induction). The results of our study indicated the presence of two levels of resistance: one at the pericarp level and one at the subpericarp level. The former was supported by KSA studies that demonstrated a role for pericarp waxes in kernel resistance (16, 17) and highlighted quantitative and qualitative differences in pericarp wax between GT-MAS:gk and susceptible genotypes (34).

KSA also confirmed sources of resistance among the inbred lines tested in Illinois field trials $(4,7)$. Subsequently, when selected re- 
sistant Illinois inbreds (MI82, CI2, and T115) were examined by KSA modified to include an A. flavus $\beta$-glucuronidase (GUS) transformant (a strain genetically engineered with a gene construct consisting of a GUS reporter gene linked to an A. flavus $\beta$-tubulin gene promoter for monitoring fungal growth), kernel resistance to fungal infection in nonwounded and wounded kernels was demonstrated both visually and quantitatively (Table 1), as was a positive relationship between the degree of fungal infection and aflatoxin levels $(4,5)$. Thus, it is now possible to accurately assess fungal infection levels and determine whether a correlation exists between infection and aflatoxin levels in the same kernels. A. flavus GUS transformants with the reporter gene linked to an aflatoxin biosynthetic pathway gene also could provide a quick, economical method of indirectly measuring aflatoxin levels (29).

KSA has several advantages that complement traditional breeding techniques (7): (i) it can be performed and repeated several times throughout the year and outside the growing season, (ii) it requires few kernels, (iii) it can detect and identify different expressed kernel resistance mechanisms, (iv) it can dispute or confirm field evaluations (e.g., identify escapes), and (v) relationships between laboratory findings and inoculations in the field can be demonstrated. Field trials are irreplaceable for confirmation of resistance; however, KSA may eliminate many preliminary field screenings and facilitate an in-depth investigation of kernel responses to fungal infection and aflatoxin production.

Molecular genetic strategies. Several of the resistant Illinois inbred lines have been incorporated into a breeding program whose major objective is to improve elite Midwestern corn lines (e.g., B73 and Mo17). In the program, a generation mean analysis mating design was employed to determine the inheritance of resistance of inbreds in crosses with B73 and Mo17 (39). In the case of several highly resistant inbreds (Tex6, LB31, CI2, and Oh513), genetic dominance was indicated. The study (39) demonstrates that selection for resistance to Aspergillus ear rot and aflatoxin production should be effective. Also, the frequency distribution of ear rot ratings and aflatoxin production of $F_{3}$ families and backcrosses to susceptible self families of Mo17 $\times$ Tex6 and B73 $\times$ LB31 point to the possibility of success in development of resistant inbreds for use in breeding commercial hybrids (39).

Chromosome regions associated with resistance to A. flavus and inhibition of aflatoxin production in corn have been identified by restriction fragment length polymorphism (RFLP) analysis of three resistant lines (R001, LB31, and Tex6) in the Illinois breeding program, after mapping populations were developed using B73 and Mo17 elite inbreds (40). In some cases, chromosomal regions were associated with resistance to Aspergillus ear rot, not aflatoxin inhibition, and vice versa, whereas other chromosomal regions were associated with both traits. The results suggest that these two traits may be at least partially under separate genetic control. Also, White et al. (40) observed that variation can exist in the chromosomal regions associated with Aspergillus ear rot and aflatoxin inhibition in different mapping populations, suggesting the presence of different genes for resistance in the different resistance germ plasm identified. RFLP technology may provide the basis for employing a successful strategy of pyramiding different types of resistance into commercially viable germ plasm, while avoiding the introduction of undesirable traits.

Identification of biochemical resistance traits. Development of resistance to fungal infection in wounded as well as intact kernels would help solve the aflatoxin contamination problem (28). Studies demonstrating subpericarp (wounded-kernel) resistance in corn kernels have led to research aimed at identifying subpericarp resistance mechanisms. When kernels of susceptible genotypes were allowed to imbibe water at $100 \% \mathrm{RH}$ at $31^{\circ} \mathrm{C}$ for 3 days prior to being subjected to the KSA protocol, aflatoxin levels were drastically reduced compared with unimbibed controls (15). Kernel proteins induced during imbibition may have inhibited fungal growth and elaboration of aflatoxins. Examination of kernel proteins of several genotypes revealed several differences between resistant and susceptible genotypes (13) and associated germination-induced synthesis of ribosome-inactivating protein (RIP) and zeamatin in imbibed susceptible kernels with decreased aflatoxin levels (14). Both zeamatin and RIP inhibit $A$. flavus growth in vitro (14). These studies $(13,14)$ implicate proteins as potentially involved in kernel resistance to $A$. flavus infection and aflatoxin production.

In a recent study (19), two kernel proteins that may contribute to resistance to aflatoxin production were identified from resistant inbred Tex6. One protein with a molecular mass of $28 \mathrm{kDa}$ inhibits A. flavus growth, while a second protein with a molecular mass of $>100 \mathrm{kDa}$ inhibits toxin formation with little effect on fungal growth. In another investigation (11), an examination of kernel protein profiles of 13 corn genotypes revealed that a $14-\mathrm{kDa}$ trypsin inhibitor protein is present at relatively high concentrations in 7 resistant genotypes and is present only in low concentrations in 6 susceptible genotypes (Fig. 1). This protein exhibits strong bioactivity against the growth of A. flavus, A. parasiticus, and a morphologically diverse group of fungi $(3,10)$. Comparisons of kernel protein profiles between susceptible and resistant genotypes may shorten the time it takes to identify resistance-associated proteins. The identification of these proteins may provide markers for plant breeders and facilitate the introduction of resistance through genetic engineering into other aflatoxin-susceptible crops. In our laboratory, cotton currently is being genetically transformed to express the $14-\mathrm{kDa}$ trypsin inhibitor (8). A quantitative trait loci mapping study also is underway to genetically characterize the $14-\mathrm{kDa}$ trypsin inhibitor's contribution to resistance in certain corn genotypes and determine its regulation (3).

\section{GENETIC RESISTANCE: CURRENT AND FUTURE RESEARCH}

Traditionally, research involving genetic resistance to preharvest kernel infection by A. flavus and production of aflatoxins has included as part of its focus the indirect protection of developing

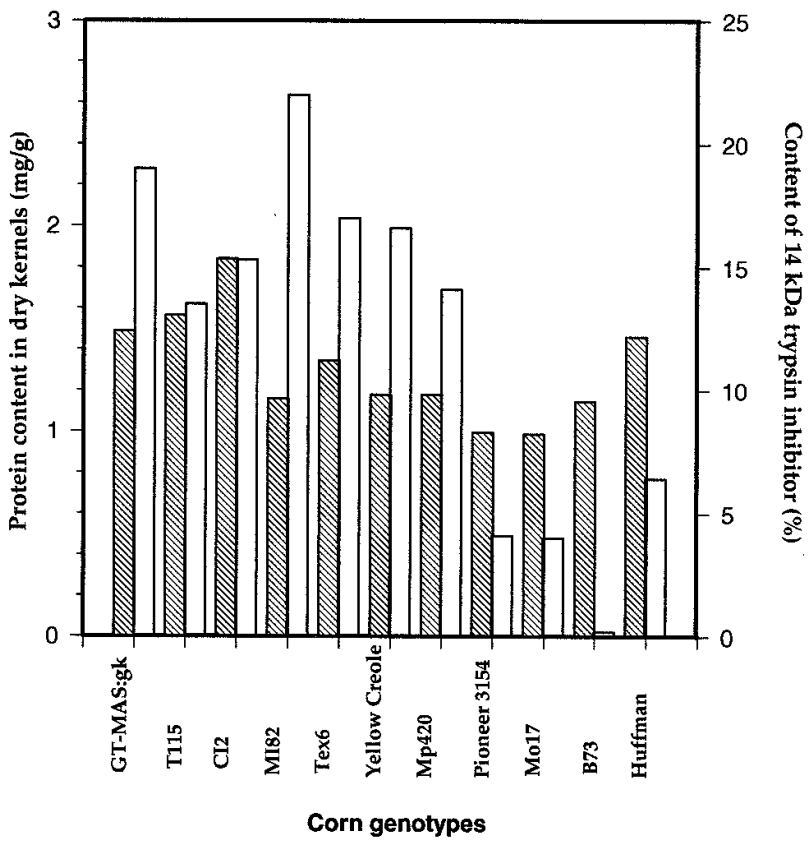

Fig. 1. Total acid-extractable proteins and relative content of 14-kDa trypsin inhibitor protein in total extracts of 11 corn genotypes. Average protein content in dry kernels was $1.391 \mathrm{mg} / \mathrm{g}$ in resistant genotypes (GT-MAS:gk to Mp420) and $1.147 \mathrm{mg} / \mathrm{g}$ in susceptible genotypes (Pioneer 3154 to Huffman) (LSD = 0.171 at $P \leq 0.05$ ). Relative content of $14-\mathrm{kDa}$ trypsin inhibitor protein in resistant genotypes was approximately two- to threefold higher than in susceptible genotypes (12). Filled bars: protein content in dry kernels; open bars: relative content of $14-\mathrm{kDa}$ trypsin inhibitor in protein extracts. 
kernels provided by husk cover and antinutritional substances in silks and the direct protection provided by kernel compounds that block fungal development and external integuments of developing kernels (26). Also, previous investigations identified resistance to drought stress and insect damage as useful, obtainable traits (26). Current research efforts are focused primarily on kernel pericarp resistance (morphologic and chemical) and kernel subpericarp biochemical resistance (antifungal proteins) to fungal infection. The resistant genotypes investigated generally seem to inhibit aflatoxin production indirectly through inhibition of fungal growth $(4,15)$.

Studies employing KSA (4), as well as other studies (21), demonstrated that kernel embryos are colonized by aflatoxinproducing fungi before endosperm tissue. Embryo viability also is necessary for expression of kernel resistance (6). It is possible that resistance, especially subpericarp, is a function of a kernel's ability to limit fungal colonization to a small area after wounding. Limiting fungal ingress may help prevent fungal spread through the kernel and interruption of whole-kernel expression of embryobased resistance mechanisms, denying the fungus easy access to the substrate most conducive to aflatoxin production (5). The high levels of aflatoxins detected in susceptible kernels often have been considered the primary result of fungal metabolic activity on an embryonic substrate; however, there is evidence that high levels of aflatoxins may result from later fungal activity in the endosperm (44).

Insect damage often is positively correlated with aflatoxin contamination; however, insects probably play a more important role in the A. flavus infection process when conditions are less favorable for the fungus (30). Under conditions more favorable to A. flavus (high temperatures and drought stress), the role of insect injury in aflatoxin contamination probably diminishes (30); $A$. flavus may even display limited parasitic abilities under such conditions (28). Research efforts focusing on development of germ plasm with resistance to insect injury acting along with resistance against fungal growth and aflatoxin production could prove beneficial.

Earlier studies evaluated corn germ plasm for drought resistance and concluded that this character appeared tightly linked to yield (26). Further investigations are needed, not only to screen, identify, and characterize drought-resistant germ plasm, but to evaluate existing sources of aflatoxin contamination resistance under drought conditions. Finally, recent elucidation of fungal aflatoxin biosynthetic pathway genes and their encoded enzymes and of regulatory genes (2) provides the potential for development of kernel mechanisms that directly inhibit aflatoxin biosynthetic pathway activity.

\section{CONCLUSIONS}

Significant control of aflatoxin contamination probably will be the result of resistant germ plasm developed either by traditional breeding or genetic engineering of plants with genes expressing either resistance against the fungus or inhibition of aflatoxin biosynthesis, especially for corn, which possesses abundant natural genetic diversity with respect to fungal infection. Naturally resistant corn germ plasm not only provides a source of resistance, but also a lesson as to the specific requirements of resistance (e.g., antifungal compounds, regulation of antifungal compounds, and physiological conditions for bioactivity). The identification of specific biochemical factors linked to resistance against A. flavus not only may contribute heavily toward eliminating aflatoxin contamination, but also may contribute to control of other fungal disease-causing agents that may be even more sensitive to plant defense compounds than is A. flavus. Recent breakthroughs in understanding the aflatoxin biosynthetic pathway allow us to understand and meet very specific conditions necessary to the process of eliminating aflatoxins. Progress made toward developing preharvest host resistance to aflatoxin contamination of corn also may provide insights into controlling other mycotoxin contamination problems.

\section{LITERATURE CITED}

1. Bhatnagar, D., Cotty, P. J., and Cleveland, T. E. 1993. Preharvest aflatoxin contamination: Molecular strategies for its control. Pages 272-292 in: Food Flavor and Safety: Molecular Analysis and Design. A. M. Spanier, N. Okai, and M. Tamura, eds. American Chemical Society, Washington, DC.

2. Brown, R. L., Bhatnagar, D., Cleveland, T. E., and Cary, J. W. 1998. Recent advances in preharvest prevention of mycotoxin contamination. Pages 351-379 in: Mycotoxins in Agriculture and Food Safety. K. K. Sinha and D. Bhatnagar, eds. Marcel Dekker, New York.

3. Brown, R. L., Chen, Z.-Y., Lax, A. R., Cary, J. W., Cleveland, T. E., Russin, J. S., Guo, B. Z., Williams, W. P., Davis, G., Windham, G. L., and Payne, G. A. 1997. Determination of maize kernel biochemical resistance to aflatoxin elaboration: Mechanisms and biotechnological tools. Page 58 in: Proc. USDA-ARS Aflatoxin Elimination Workshop. National Agricultural Library, Beltsville, MD.

4. Brown, R. L., Cleveland, T. E., Payne, G. A., Woloshuk, C. P., Campbell, K. W., and White, D. G. 1995. Determination of resistance to aflatoxin production in maize kernels and detection of fungal colonization using an Aspergillus flavus transformant expressing Escherichia coli $\beta$-glucuronidase. Phytopathology 85:983-989.

5. Brown, R. L., Cleveland, T. E., Payne, G. A., Woloshuk, C. P., and White, D. G. 1997. Growth of an Aspergillus flavus transformant expressing Escherichia coli $\beta$-glucuronidase in maize kernels resistant to aflatoxin production. J. Food Prot. 60:84-87.

6. Brown, R. L., Cotty, P. J., Cleveland, T. E., and Widstrom, N. W. 1993. Living maize embryo influences accumulation of aflatoxin in maize kernels. J. Food Prot. 56:967-971.

7. Campbell, K. W., and White, D. G. 1995. Evaluation of corn genotypes for resistance to Aspergillus ear rot, kernel infection, and aflatoxin production. Plant Dis. 79:1039-1045.

8. Cary, J. W., Rajasekaran, K., Delucca, A. J., Jacks, T. J., Lax, A. R., Cleveland, T. E., Chlan, C., and Jaynes, J. 1997. Transformation and analysis of cotton and tobacco tissues expressing antifungal proteins and peptides. Page 55 in: Proc. USDA-ARS Aflatoxin Elimination Workshop. National Agricultural Library, Beltsville, MD.

9. CAST. 1979. Aflatoxins and other mycotoxins: An agricultural perspective. Counc. Agric. Sci. Technol. Rep. CAST, Ames, IA.

10. Chen, Z.-Y., Brown, R. L., Lax, A. R., Guo, B. Z., Cleveland, T. E., and Russin, J. S. 1997. A maize kernel trypsin inhibitor is associated with resistance to Aspergillus flavus infection. Page 34 in: Proc. USDA-ARS Aflatoxin Elimination Workshop. National Agricultural Library, Beltsville, MD.

11. Chen, Z.-Y., Brown, R. L., Lax, A. R., Guo, B. Z., Cleveland, T. E., and Russin, J. S. 1998. Resistance to Aspergillus flavus in corn kernels is associated with a 14-kDa protein. Phytopathology 88:276-281.

12. Diener, U. L., Cole, R. J., Sanders, T. H., Payne, G. A., Lee, L. S., and Klich, M. A. 1987. Epidemiology of aflatoxin formation by Aspergillus flavus. Annu. Rev. Phytopathol. 25:249-270.

13. Guo, B. Z., Brown, R. L., Lax, A. R., Cleveland, T. E., Russin, J. S., and Widstrom, N. W. 1998. Protein profiles and antifungal activities of kernel extracts from corn genotypes resistant and susceptible to Aspergillus flavus. J. Food Prot. 61:98-102.

14. Guo, B. Z., Chen, Z.-Y., Brown, R. L., Lax, A. R., Cleveland, T. E., Russin, J. S., Mehta, A. D., Selitrennikoff, C. P., and Widstrom, N. W. 1997. Germination induces accumulation of specific proteins and antifungal activities in corn kernels. Phytopathology 87:1174-1178.

15. Guo, B. Z., Russin, J. S., Brown, R. L., Cleveland, T. E., and Widstrom, N. W. 1996. Resistance to aflatoxin contamination in corn as influenced by relative humidity and kernel germination. J. Food Prot. 59:276-281.

16. Guo, B. Z., Russin, J. S., Cleveland, T. E., Brown, R. L., and Damann, K. E. 1996. Evidence for cutinase production by Aspergillus flavus and its possible role in infection of corn kernels. Phytopathology 86:824-829.

17. Guo, B. Z., Russin, J. S., Cleveland, T. E., Brown, R. L., and Widstrom, N. W. 1995. Wax and cutin layers in maize kernels associated with resistance to aflatoxin production by Aspergillus flavus. J. Food Prot. 58:296300 .

18. Haumann, F. 1995. Eradicating mycotoxins in food and feeds. Inform 6: 248-256.

19. Huang, Z., White, D. G., and Payne, G. A. 1997. Corn seed proteins inhibitory to Aspergillus flavus and aflatoxin biosynthesis. Phytopathology 87:622-627.

20. Jones, R. K. 1987. The influence of cultural practices on minimizing the development of aflatoxin in field maize. Pages 136-144 in: Aflatoxin in Maize: Proc. Workshop. M. S. Zuber, E. B. Lillehoj, and B. L. Renfro, eds. International Maize and Wheat Improvement Center, Mexico, D.F.

21. Keller, N. P., Butchko, R. A. E., Sarr, B., and Phillips, T. D. 1994. A visual pattern of mycotoxin production in maize kernels by Aspergillus spp. 
Phytopathology 84:483-488.

22. King, S. B., and Scott, G. E. 1982. Field inoculation techniques to evaluate maize for reaction to kernel infection by Aspergillus flavus. Phytopathology 72:782-785.

23. King, S. B., and Wallin, J. R. 1983. Methods for screening corn for resistance to kernel infection and aflatoxin production by Aspergillus flavus. Pages 77-80 in: Aflatoxin and Aspergillus flavus in Corn. U. L. Diener, R. L. Asquith, and J. W. Dickens, eds. South. Coop. Bull. 279. Auburn University, Auburn, AL.

24. Klich, M. A., Tiffany, L. H., and Knaphus, G. 1994. Ecology of the aspergilli of soils and litter. Pages 329-353 in: Aspergillus Biology and Industrial Applications. J. W. Bennett and M. A. Klich, eds. ButterworthHeineman, Boston.

25. Lillehoj, E. B. 1987. The aflatoxin-in-maize problem: The historical perspective. Pages 13-32 in: Aflatoxin in Maize: Proc. Workshop. M. S. Zuber, E. B. Lillehoj, and B. L. Renfro, eds. International Maize and Wheat Improvement Center, Mexico, D.F.

26. Lisker, N., and Lillehoj, E. B. 1991. Prevention of mycotoxin contamination (principally aflatoxins and Fusarium toxins) at the preharvest stage. Pages 689-719 in: Mycotoxins and Animal Foods. J. E. Smith and R. S. Henderson, eds. CRC Press, Boca Raton, FL.

27. Mckenzie, K. S., Sarr, A. B., Mayura, K., Bailey, R. H., Miller, D. R., Rogers, T. D., Norred, W. P., Voss, K. A., Plattner, R. D., Kubena, L. F., and Phillips, T. D. 1997. Oxidative degradation and detoxification of mycotoxins using a novel source of ozone. Food Chem. Toxicol. 35:807-820.

28. Payne, G. A. 1992. Aflatoxin in maize. Crit. Rev. Plant Sci. 10:423-440.

29. Payne, G. A. 1997. Characterization of inhibitors from corn seeds and the use of a new reporter construct to select corn genotypes resistant to aflatoxin accumulation. Pages 66-67 in: Proc. USDA-ARS Aflatoxin Elimination Workshop. National Agricultural Library, Beltsville, MD.

30. Payne, G. A. 1998. Process of contamination by aflatoxin-producing fungi and their impact on crops. Pages 279-306 in: Mycotoxins in Agriculture and Food Safety. K. K. Sinha and D. Bhatnagar, eds. Marcel Dekker, New York.

31. Payne, G. A., Cassel, D. K., and Adkins, C. R. 1986. Reduction of aflatoxin contamination in corn by irrigation and tillage. Phytopathology 76 : 679-684.

32. Payne, G. A., Hagler, W. M., Jr., and Adkins, C. R.. 1988. Aflatoxin accumulation in inoculated ears of field-grown maize. Plant Dis. 72:422-424.

33. Park, D. L., Lee, L. S., Price, R. L., and Pohland, A. E. 1988. Review of decontamination by ammoniation: Current status and regulation. J. AOAC 71:685-703.
34. Russin, J. S., Guo, B. Z., Tubajika, K. M., Brown, R. L., Cleveland, T. E., and Widstrom, N. W. 1997. Comparison of kernel wax from corn genotypes resistant or susceptible to Aspergillus flavus. Phytopathology 87:529533.

35. Scott, G. E., and Zummo, N. 1988. Sources of resistance in maize to kernel infection by Aspergillus flavus in the field. Crop Sci. 28:505-507.

36. Shotwell, O. 1983. Aflatoxin detection and determination in corn. Pages 38-45 in: Aflatoxin and Aspergillus flavus in Corn U. L. Diener, R. L. Asquith, and J. W. Dickens, eds. South. Coop. Bull. 279. Auburn University, Auburn, AL.

37. Sinha, K. K. 1998. Detoxification of mycotoxins and food safety. Pages 381-405 in: Mycotoxins in Agriculture and Food Safety. K. K. Sinha and D. Bhatnagar, eds. Marcel Dekker, New York.

38. Tucker, D. H., Jr., Trevathan, L. E., King, S. B., and Scott, G. E. 1986. Effect of four inoculation techniques on infection and aflatoxin concentration of resistant and susceptible corn hybrids inoculated with Aspergillus flavus. Phytopathology 76:290-293.

39. White, D. G., Rocheford, T. R., Kaufman, B., and Hamblin, A. M. 1995. Further genetic studies and progress on resistance to aflatoxin production in corn. Page 7 in: Proc. USDA-ARS Aflatoxin Elimination Workshop. National Agricultural Library, Beltsville, MD.

40. White, D. G., Rocheford, T. R., Kaufman, B., and Hamblin, A. M. 1995. Chromosome regions associated with resistance to Aspergillus flavus and inhibition of aflatoxin production in maize. Page 8 in: Proc. USDA-ARS Aflatoxin Elimination Workshop. National Agricultural Library, Beltsville, MD.

41. Widstrom, N. W., McMillan, W. W., and Wilson, D. 1987. Segregation for resistance to aflatoxin contamination among seeds on an ear of hybrid maize. Crop Sci. 27:961-963.

42. Wilson, D. M., Sydenham, E. W., Lombaert, G. A., Trucksess, M. W., Abramson, D., and Bennett, G. A. 1998. Mycotoxin analytical techniques. Pages 135-182 in: Mycotoxins in Agriculture and Food Safety. K. K. Sinha and D. Bhatnagar, eds. Marcel Dekker, New York.

43. Windham, G. L., and Williams, W. P. 1998. Aspergillus flavus infection and aflatoxin accumulation in resistant and susceptible maize hybrids. Plant Dis. 82:281-284.

44. Woloshuk, C. P., Cavaletto, J. R., and Cleveland, T. E. 1997. Inducers of aflatoxin biosynthesis from colonized maize kernels are generated by an amylase activity from Aspergillus flavus. Phytopathology 87:164-169.

45. Wyllie, T. D., and Morehouse, L. G. 1978. Introduction. Page vii in: Mycotoxic Fungi, Mycotoxins, Mycotoxicoses: An Encyclopedic Handbook. Vol. 3. T. D. Wyllie and L. G. Morehouse, eds. Marcel Dekker, New York. 